\title{
FACTORS INFLUENCING MECHANICAL PROPERTIES OF POLYURETHANE FOAMS USED IN COMPRESSIBLE FLEXOGRAPHIC SLEEVES
}

\author{
Saša Petrović (D), Nemanja Kašiković (D), Željko Zeljković (iD, Rastko Milošević \\ University of Novi Sad, Faculty of Technical Sciences, Department of Graphic Engineering and \\ Design, Novi Sad, Serbia
}

\begin{abstract}
Polyurethanes are a group of polymers which are in many ways different from other types of plastic. They are used in many different areas due to the fact that many different chemicals can be used during their synthesis, resulting in a variety of structures. Sleeves are comprised of hard base often covered with compressible polyurethane (PU) foam layer. PU foam layer can have different composition and level of porosity which are the main factors influencing compressibility of the sleeve and therefore its area of use. Sleeves are also one of the least researched components in the flexographic printing process. However, mechanical properties of the polyurethane, its fatigue, lifespan and parameters influencing all of them have been extensively investigated in different areas and for different types and formulations of polyurethane. The aim of this paper is to investigate factors influencing mechanical properties of polyurethane foams used in compressible flexographic sleeves. Investigated parameters are foam density, level of strain and strain rate, influence of microstructure under different conditions and parameters influencing creep and stress relaxation. The review of the existing literature regarding mechanical properties of the $P U$ foams makes it possible to select the parameters with the greatest possible influence on the flexographic printing process, as well as to find the most suitable methods to investigate the effect of exploitation on sleeve properties. As a large number of parameters influencing $P \cup$ foam mechanical properties are fixed during printing, it can be concluded, through the review of the existing literature, that the main parameters to be investigated are the resilience of the sleeve compressible layer during cyclic compression testing (residual strain), maximum stress, Young's modulus, hysteresis loss, and creep and stress relaxation during cyclic compression testing with strain retention.
\end{abstract}

Keywords: flexography, compressible sleeves, polyurethane foams, mechanical properties

\section{INTRODUCTION}

Packaging is nowadays, a multi-disciplinary field, a rapidly evolving science and a dynamic industry with continuous positive indicators (Politis, 2018), with the print quality being determined by many factors connected with printing process (Izdebska, 2015). Manufacturers of flexographic printing components are focused towards development of new printing plates, inks, anilox engraving techniques, stickyback tapes and sleeves, all of which have a significant impact on the product quality.

Sleeves are comprised of hard base often covered with compressible polyurethane (PU) foam layer. PU foam layer can have different composition and level of porosity which are the main factors influencing compressibility of the sleeve and therefore its area of use. Sleeves are also one of the least researched components in the flexographic printing process. However, mechanical properties of the polyurethane, its fatigue, lifespan and parameters influencing all of them have been extensively investigated in different areas and for different types and formulations of polyurethane.

Polyurethanes are a group of polymers which are in many ways different from other types of plastic. They are used in many different areas due to the fact that many different chemicals can be used during their synthesis, resulting in a variety of structures. Polyurethanes are currently one of the most universal, widespread and investigated materials in the world (Zia et al, 2014). These materials combine durability and toughness of metal with the elasticity of the rubber, making them suitable alternatives for metal, plastic or rubber in different products (Rafiee, 2015; Priscariu, 2011). Namely, PU elastomers have found use in a large number of various products, i.e. inks, liquid coatings, elastomers, foams, footwear, furniture, tires, construction materials, machines, sportswear, electronics, etc. (Akindoyo et al, 2016; Engels et al, 2013). They have outstanding capability of recovery from the compression or tension stress, and can withstand exposure to a large number of environment factors (Chattopadhyay and Webster, 2009; Zia et al, 2007).

Among the wide spectrum of possible shapes and types of PU, the most common are PU foams. Namely, in 2018., the PU foam market was estimated at 50.21 billion USD, and is expected to rise up to 79.77 billion USD until 2023. (Markets and Markets, 2018). Apart from that, PU foams make up half of the 
polymer foams market (Szycher, 2006). Based on the mechanical properties and crosslinking density, PU foams are classified in two groups, rigid and flexible (Randall and Lee, 2003; Wirpsza and Kemp, 1993).

\section{PARAMETERS INFLUENCING MECHANICAL PROPERTIES OF POLYURETHANE FOAMS}

\subsection{Foam density}

Density is mass of substance per its unit of volume. It is most often expressed in $\mathrm{g} / \mathrm{cm}^{3}$, while its values can be obtained from the sample of any size. Density is not correlated to the size of pores. Namely, foams with coarse and fine pores may have the same density. Density is also not a measure of strength, stiffness or load-bearing capacity. Those are defined by the measure of deflection of the compressive force defined by the stress required to keep the sample compressed by $25 \%$ after one minute. The higher the stress value, the greater the ability of the foam to carry the load (QFP, 2019).

The authors (Chen et al, 2015) concluded that expanded polystyrene of higher density has a higher energy absorption capacity than when its density is lower.

(De Vries, 2009) through research defined the influence of relative foam density on the stress-strain curve (Graph 1). As the density increases, so does the Young's modulus, the plateau modulus, and the elastic collapse stress, and the strain at which densification begins decreases. More about the mechanisms that lead to that will be stated in the influence of the microstructure, i.e. the cells in the material.

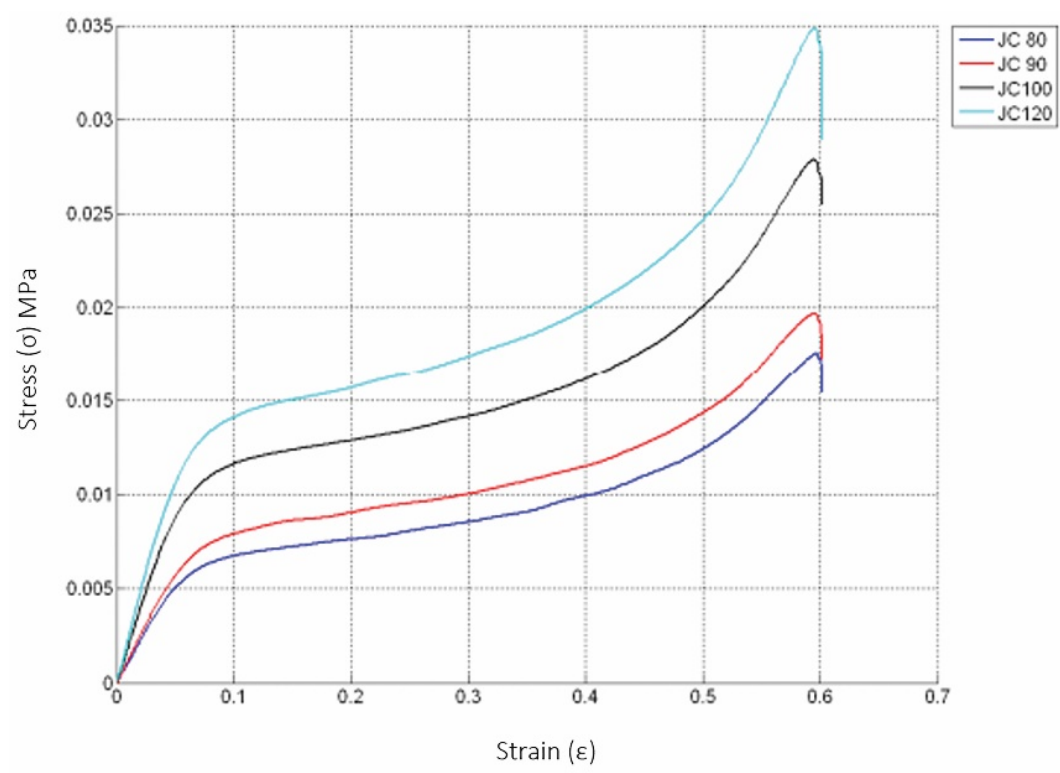

Graph 1: Stress-strain curves of JC foams with different densities (80,90, 100 and 120) at a constant strain rate (de Vries, 2009)

The yield strength increases by almost $100 \%$ with an increase in foam density of only $20 \%$ (Lu et al, 2016). The density of the foam is controlled by the amount of gas released during the reaction of water with the isocyanate (Saint Michel et al, 2006).

According to the authors (Alzoubi et al, 2014), the elastic properties depend on the relative density of the foam, the shape and size of the cross section of the struts, the Young's modulus and the Poisson's ratio. Foams such as flexible polyurethane foam are cellular solids whose microstructure consists of a network of struts (open cells) or panels (closed cells) as shown in Figure 1. The cavities that are surround by them create cells that are filled with gas, liquid, or just open. 


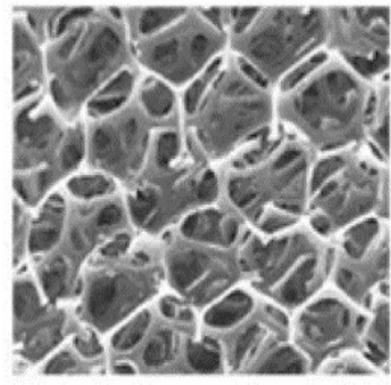

a)

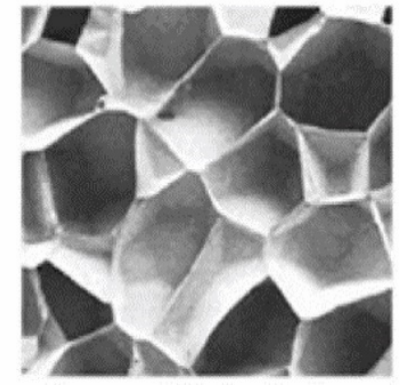

b)

Figure 1: Microscopic image of a foam with a) open; b) closed cells (Alzoubi et al, 2014)

The authors (Gibson and Ashby, 1988) and (Alzoubi et al, 2011) described the effects of foam density on the mechanical properties of cellular solids with closed and open cells. (Gibson and Ashby, 1982) described the ratios of densities as a function of the modulus of elasticity to the ratios of the yield strengths of open cell foams for a linear elastic region in the manner shown by equation 1.

$\frac{E^{*}}{E_{S}}=C_{1}\left(\rho^{*} / \rho_{S}\right)^{2}$

where $E^{*}$ is Young's modulus of the foam, Es Young's modulus of cell wall material, $\rho^{*}$ and $\rho_{S}$ are respectively foam and foam cell wall material densities and $C_{1}$ is the constant obtained through testing of a number of foam samples with different densities.

Uniaxial quasi-static compression tests were performed on all foam samples. It was concluded that Young's modulus of elasticity increases with increasing foam density. The modulus of elasticity increases rapidly in foam samples with higher densities, and the stresses measured at $5 \%$ and $70 \%$ of the strain increase in parallel with the density (Alzoubi et al, 2014).

It has been experimentally proven that hysteresis (Kreter, 1985; Lee, 1985; Cavender, 1990) and reduction of stress due to fatigue (Dwyer, 1976; Courtney et al, 1989) decrease with increasing foam density. These conclusions are supported by the observations of the author (Dwyer, 1976) who showed that with flexible polyurethane foams, density reduction is not the main reason for increased fatigue (i.e. stress reduction) but water levels and physical inflating agents that affect foam durability. He concluded that higher density foams show less fatigue loss, and therefore less hysteresis through a reduction in the urea content in the solid polymer.

\subsection{Level of strain and strain rate}

According to (Molded Dimension, LLC., 2019), the increase in the initial strain is followed with an increase in the level of creep.

(De Vries, 2009) has shown on the example of commercially available open-cell PU foam that the zone of elasticity is initially linear. However, at the strain level of about $4 \%$, the slope of the stress-strain curve begins to decrease and at strain level of around $10 \%$ forms a plateau of elastic collapse. At a strain level of about $60 \%$, densification occurs. After compression, the foam sample returns almost completely to its initial dimensions, which means that the deformation is completely elastic. At a strain level of about $60 \%$, stress relaxation was also observed. Those three characteristic zones of the stress-strain curve during compression are typical of elastomeric foams (Gibson and Ashby, 1988).

In addition to the strain levels, the strain rate can have a large influence on the mechanical properties of the polymer. As the application of polymers expanded, so did the influence of the strain rate factor on researchers' interest. In recent years, several experimental approaches have been developed to study the influence of strain rate on the mechanical properties of polymers (Sarva et al, 2007; Río and Rodríguez, 2010; Mulliken and Boyce, 2006). One of the most important characteristics used to evaluate the mechanical properties of a material is the stress-strain curve. Polymers can be classified into different classes according to the parameters in the region of the yield strength.

(Lu et al, 2016) experimentally concluded that the Young's modulus and the elastic buckling stress of the foam are obviously dependent on the strain rate. The values of the Young's modulus and the elastic buckling stress at a strain rate of $200 \mathrm{~s}^{-1}$ are about five times or twice as high as those at $0.1 \mathrm{~s}^{-1}$. During the unloading, hysteresis behaviour is noticeable, where the unloading strain is late compared to the stress, but after a sufficient time it returns to zero with a small permanent deformation. 
In the research of the authors (Omar et al, 2011a), all tested samples showed a growing trend in the yield strength with increasing strain rate. In contrast, the strain at the elastic limit decreases significantly with increasing strain rate. This decrease is attributed to an increase in adiabatic temperature within the sample with increasing strain rate (Omar et al, 2011b; Guo and Li, 2007) where the accumulated heat weakens the material. Another explanation for this phenomenon was given by the authors (Nakai and Yokoyama, 2008) where it is directly related to the accumulation of micro damage during deformation. The authors stated that the higher the strain rate, the more serious the damage done to the sample as more cracks must occur due to the adaptation to larger strains at higher rates. The result is that the combination of both phenomena causes a decrease in the strain of all polymeric materials at the elastic limit with an increase in the strain rate.

Theoretically, under impact loads compression can be classified into high or low energy compression (Omar et al, 2011a). It is believed that high energy compression usually leads to instantaneous failure of the material. However, damage from low-energy compression is difficult to detect and can lead to sudden and catastrophic failures. The absorbed energy capacity was one of the main parameters in the work of (Omar et al, 2011a). Energy absorption is most often determined by measuring the area under the stress-strain curve to a certain strain. In the aforementioned work, this strain limit was $2.5 \%$. The relationship between the absorbed energy and the strain rate is such that the strain energy increases with increasing velocity. The authors noted that tested polymers have different stress-strain curves and are therefore classified into classes of elastic and brittle polymers. The conclusions drawn from their research are that the mechanical properties of polymers largely depend on the strain rate. The yield strength, the compression modulus and the compressive strength increase in proportion to the increase in the strain rate, and the strain at the elastic limit opposite to them shows a gradual decrease.

(Wang et al, 2016) conducted quasi-static and cyclic deformation tests of polycarbonate ABS at different strain rates $\left(10^{-4}, 10^{-3}\right.$ and $\left.10^{-2} \mathrm{~s}^{-1}\right)$ and different temperatures $\left(20,50\right.$, and $\left.80^{\circ} \mathrm{C}\right)$. Cyclic compression tests were performed at different strain rates $\left(10^{-4}, 10^{-3}\right.$ and $\left.10^{-2} \mathrm{~s}^{-1}\right)$ at room temperature $\left(20^{\circ} \mathrm{C}\right)$. The level of strain was at least $80 \%$. It was concluded that the mechanical behaviour of polycarbonate ABS is greatly influenced by the strain rate, and also by the temperature when subjected to a monotonic load. Yield strength increases significantly with an increase in strain rate or a decrease in temperature, and the stress at higher strain rates grows faster than at lower strain rates. Also, at higher strain rates, the Young's modulus is significantly higher. The behaviour in the cyclic test is also dependent on the strain rate and is not linearly elastic during unloading and reloading. As the strain rate increases, so does the stress during loading and reloading after unloading.

When expanded polystyrene is subjected to compression, the air trapped inside the cells is compressed and a viscous force is created. Viscous forces increase with the strain rate (Ouellet et al, 2006). (Croop and Lobo, 2009) found that the behaviour of expanded polystyrene is such that it is stiffer as the air trapped inside the cells creates "cushions" due to the inability to leave the material at high strain rates. (Chakravarty et al, 2003) found that changes in the properties of foam materials during higher strain rate deformations are due to the variable nature of the gas during compression. The influence of strain rate has also been addressed in the work of (Di Landro et al, 2002). They found that with a large increase in the strain rate, the modulus of elasticity of the material also increased slightly. Also, the yield strength and the plateau stress increase with increasing strain rate (Tedesco et al, 1993). A similar thing was observed by (Song et al, 2005) when they concluded that the modulus of elasticity increases with an increase in the strain rate. (Chen et al, 2015) concluded that when the strain rate is greater than $113 \mathrm{~s}^{-1}$, the compressive strength of expanded polystyrene increases rapidly, but the level of strain during densification decreases. The Young's modulus does not show a significant dependence on the strain rate in the tested range $\left(1-280 \mathrm{~s}^{-1}\right)$.

By conducting experiments on porous polypropylene ( $94 \%$ porosity) with a closed cell structure (Yonezu et al, 2016) found that the macroscopic stress-strain curve shows the plateau zone when the material undergoes plastic deformation, and that the influence of strain rate is expressed in material behaviour in the plateau zone.

\subsection{Influence of microstructure on foam properties under different conditions}

It is known that at the macroscopic level, polymer foams are very sensitive to the strain rate. For a large number of polymer foams, an exponential dependence of stress at material failure and strain rate has been observed (Ouellet et al, 2006). It is also known that the transition in sensitivity to the strain rate of these materials mainly occurs at strain rates greater than $103 \mathrm{~s}^{-1}$, where the stress at failure and modulus 
of elasticity of the material rapidly follow the increase in strain rate (Song et al, 2005; Zhao, 1997; Nagy et al, 1974; Yi et al, 2006; Mulliken and Boyce, 2006; Koohbor et al, 2016).

A large number of studies involving the microstructure of open-cell foams have shown that most of the cells within the foam are to some extent elongated in a certain direction originating from the production process. Using X-ray tomography, (Perrot et al, 2007) measured a ratio of 1.26 to 1.56 in open-cell aluminum foams. (Jang et al, 2008) and (Gong et al, 2005) investigated the geometric characteristics of a whole series of open-cell polyester urethane foams. The research included the geometry of cells and struts, as well as the arrangement of material in struts and nodes. The conclusion they derived is that the anisotropic ratio is generally between 1.2 and 1.5 .

(Lu et al, 2016) used new and 30 year old foam samples in their study. Although the average cell size is almost equal to the cell size of the new foam $(200 \mu \mathrm{m})$, the shape of the cells is slightly different. Namely, the cells of the new foam have an oval shape (Figure 2).

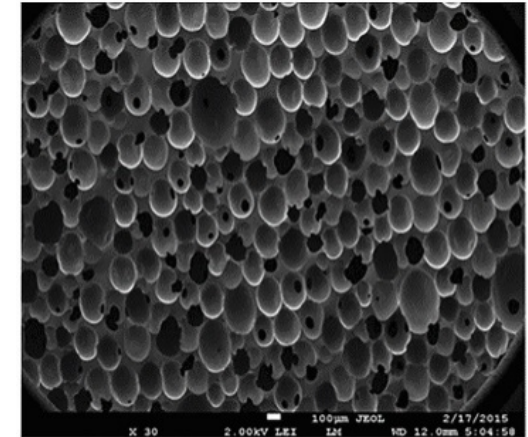

a)

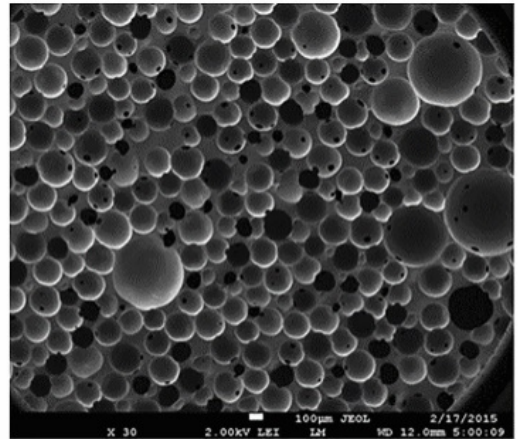

b)

Figure 2: Microscopic image of cells in a) new; b) 30 year old foam (Lu et al, 2016)

According to the model of authors (Gibson and Ashby, 1988), closed cell foams are described as complex cuboidal structures constructed of struts and walls. The strength of closed cells depends on three components. The flexibility of the struts (as with open cell foams), the stretching of the cell walls and the pressure of the gas trapped in the cells. (Saint Michel et al, 2006) and (Lu et al, 2015) found that open-cell foams with sections of equilateral triangles show significantly greater asymmetry in strength than those with square or circular sections, while circular sections showed the smallest asymmetry.

The pronounced sensitivity of polymer foams to the strain rate has two sources. One is the release of gas trapped inside the cells (in the structure of closed cells), and the other is the mechanical response of the solid parent material (Sun and Li, 2015). The first source is the main cause that contributes to the pronounced sensitivity of closed cell foams to the strain rate, as well as to their hardening (Di Landro et al, 2002; Bouix et al, 2009; Mondal et al, 2009).

(Bouix et al, 2009) investigated the contribution of gas release to strain rate sensitivity and hardening of expanded closed cell polypropylene foam by performing a quasi-static and dynamic test on submerged samples. The analysis was performed in relation to the formation of air bubbles on the surface of the samples as a consequence of the release of gas that accompanies the deformation and tearing of closed cells inside the material.

The contribution of the mechanical behaviour of the parent polymer material to the macroscopic response to foam deformation has been investigated mostly through deformation behaviour at the cellular level. However, most research in this field, conducted on such small dimensions is based on micromechanical simulations without experimental evidence (Pal et al, 2010; Alkhader et al, 2008; Brydon et al, 2005; Mills et al, 2009; Li et al, 2003).

Relatively recent theoretical studies have shown that deformation at low forces (lesser than the elastic buckling stress) is associated with bending of cellular elements (Figure 3) (Gibson and Ashby, 1988; Warren and Kraynik, 1988) rather than with normal deformation of struts parallel to the force vector, as was previously assumed, e.g. in the work of authors (Gent and Thomas, 1963). 

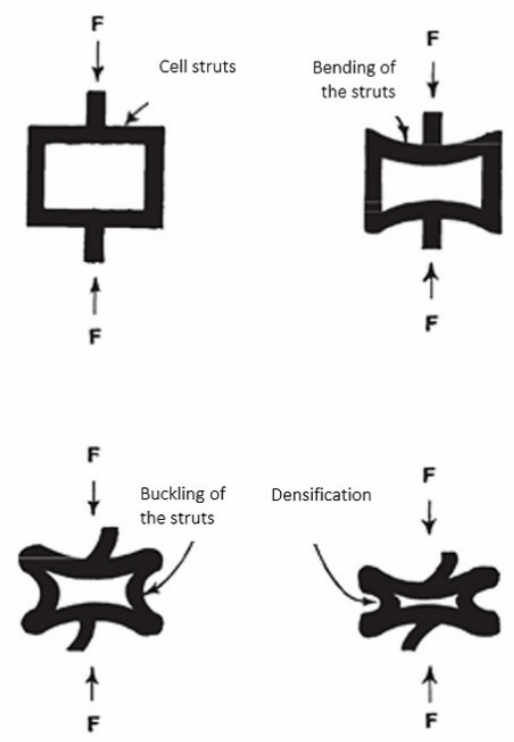

Figure 3: Bending of the cell walls parallel to the force vector

(Koohbor et al, 2018) showed that under conditions where there is no significant influence of the strain rate on the strength and modulus of elasticity of the parent polymer, elastic buckling and failure due to brittleness inside the thinner cell walls become competing failure modes. Elastic buckling is a more likely failure mode in areas where the cell walls are very thin. On the other hand, brittle failure is evidently the dominant mode of failure within thicker cell walls. In addition, they proved that as the strain rate increases, so does the difference between the critical stresses for all material failure modes. Thus, although the failure mode due to brittleness (Figure 4. c) is the main failure mode for all strain rates, the chances of failure occurring due to elastic buckling (Figure 4. a) and/or plastic collapse (Figure 4. b) grow. The overlap of these modes at higher strain rates occurs due to a significant increase in the yield strength of the parent polymer. Although the modulus of elasticity of a material increases, its growth is not at the same rate as the increase in the yield strength. As elastic buckling is based on the elastic response of cell walls to deformation, its growth with increasing strain rate is less significant. This leads to overlapping of the curves of the three failure modes at higher rates. The global deformation and the strain rate on the sample at the macro level differ significantly (are at least one magnitude less) than those at the local level of the cell walls.

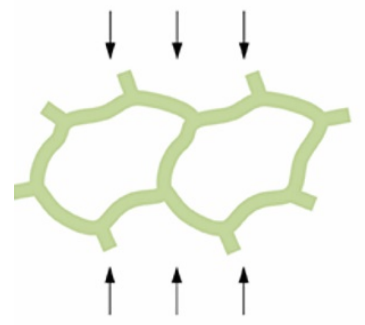

a)

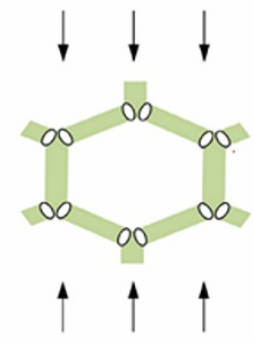

b)

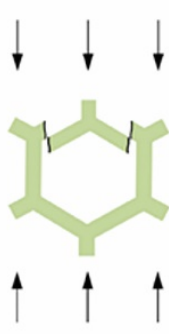

c)

Figure 4: Schematic representation of cell deformation due to a) elastic buckling; b) plastic collapse; c) brittleness (Koohbor et al, 2018)

The elastic response of a linear character in foam is controlled by bending the cell walls, and in the case of closed cells by stretching of the cell walls. Young's modulus (E) is the initial slope of the stress-strain curve of the polymer foam. For small strains, the foam will have an elastic response. In this zone, the compression stress can be expressed by equation 2 .

$\sigma=E x \varepsilon$

where $\sigma$ is stress, and $\varepsilon$ strain. 
During compression, the plateau of plastic behaviour is associated with cell collapse. The plateau is different for elastomeric and elastoplastic foams. In elastomeric foams, the plateau is determined by elastic buckling (Gibson and Ashby, 1999). With pure elastomeric foams, there is no plastic deformation, but elastoplastic materials also have a plasticity zone.

When the cells undergo almost complete collapse, the opposite cell walls touch and further deformation compresses only the solid, resulting in a final zone of rapidly increasing stress relative to the strain known as the densification zone with a slope approaching the Young's modulus of solid-full polymers at the limit of deformation.

If the density is low, foams with open cells are deformed primarily by bending the cell walls. With increasing relative density $(R>0.1)$, the contribution of simple stretching or compression of cell walls becomes more significant. There are models in the literature that predict the Young's modulus of foam based on the shape of the cells in the structural sequence, such as the structure of a honeycomb (Mills, 2007; Gibson and Ashby, 1988). In practice, cell shapes and structural sequences are not like that.

In closed cell foams, the cell walls twist and elongate on contact, and the membranes that form the face and back of the cell stretch, increasing the contribution of the axial strength of the cell walls to the modulus of elasticity. If the membranes do not tear, the compression of the air inside the cells also increases the strength. Therefore, for Young's modulus there are three main contributors to the initial foam hardness (de Vries, 2009).

During compression, the stress-strain curve for polymer foams has an extending plateau at a stress that does not change significantly. This stress level is called the elastic collapse stress, and the slope of the plateau is the modulus of the plateau. The elastic collapse of the foam is caused by the elastic bending of the cell walls. When the elastomeric foam with open cells compresses, the cell walls will slowly bend to the critical stress at which buckling will occur.

Another factor that contributes to the dependence on the strain rate comes from the fluid in the foam cells. When the foam compresses, the fluid deforms or is forced to flow from cell to cell. In open cell foams, air is expelled from the foam during compression. This causes viscous forces that depend on the strain rate (de Vries, 2009).

Unlike the influence on the mechanical properties of foam, the size of the cells greatly affects the properties of air flow. In closed cell foams, this is irrelevant as long as the membranes do not tear, thus releasing air inside the foam. When the open cell foam is compressed, air is expelled from it, which requires a certain amount of work that opposes the viscous forces. The higher the strain rate, the faster the air flow, and thus the work invested to overcome the viscous forces.

Skochdopole and Ruben gave a qualitative model that suggests that the air inside the cells and the microstructures of closed-cell polymers act in parallel during deformation. The model is simple and is based on the addition of the stress of the polymer structure to the stress originating from the air inside the cells (Mills, 2007).

In the research of the author (de Vries, 2009), it was observed that the strain rate affects the Young's modulus of the examined open-cell polymer foam. This influence comes from the inside of the material, that is, from the polymer walls of the cells. Therefore, it was concluded that the Young's modulus was determined by the parameters of the cell wall material and the complex microstructure of the foam, as well as the strain rate. Therefore, it would be more correct to call the zone of elastic response with a linear character a viscoelastic zone. For the tested foam, it was observed that the Young's modulus increases with increasing strain rate and that in most zones of the curve the sample size has no effect, as well as that the air flow does not contribute significantly to the stress level. Thicker foams (with smaller pores) will contribute to the influence of air flow due to higher viscosity forces and the work required to expel air.

\subsection{Parameters influencing the creep and stress relaxation}

(Tobushi et al, 2002) investigated the phenomena of creep and stress relaxation of polymer memory foam. They concluded that the creep is higher if the initial strain is smaller. Also, the creep and recovery from deformation are very pronounced at temperatures lower than the glass transition temperature $\left(T_{g}\right)$. In addition, they concluded that after some time, the stress after relaxation is proportional to the initial stress. The level of stress relaxation is large below the temperature $T_{g}$, but above that temperature it is small. The stress relaxation level is also high if the strain rate is also high. With large strain and maintaining of a constant stress above the temperature $T_{g}$, irreversible deformation occurs. When a large 
strain is constantly maintained above the temperature $T_{g}$, almost complete stress relaxation occurs and the deformation becomes fixed.

The level of stress relaxation also depends on the history of material deformations and temperature fluctuations during measurements (Derham, 1973).

According to (Molded Dimension, LLC., 2019), a loading that allows occasional periods of material recovery will lead to a smaller creep than continuous loading. However, continuous vibration loading will lead to increased creep due to internal heat generation. Also, after a certain period of time, the creep reaches the plateau and becomes almost constant, and the creep level itself is represented by a function of the stress level.

(Qi and Boyce, 2005) during loading and unloading of materials periodically paused testing for 60s at strain levels of $20 \%, 40 \%, 60 \%$ and $80 \%$ and measured the stress response, i.e. stress relaxation at constant strain. During loading, the stress decreased in the strain retention phases, while during unloading the stress increased in the retention phases. This behaviour is typical time-dependent behaviour of some more conventional elastomeric materials (e.g., in studies by the authors (Lion, 1996) and (Bergstrom and Boyce, 1998)).

(Petrů and Novák, 2017) subjected different types of polyurethane foams to strain levels of $10 \%, 25 \%$, $50 \%$, and $65 \%$ over duration of 3600s while measuring stress relaxation. Their research concludes that regardless of the type of polyurethane foam, stress relaxation increases with increasing initial strain.

\section{CONCLUSIONS}

Knowledge of the factors influencing $\mathrm{PU}$ foam properties enables further research regarding characterization of the flexographic sleeves. The review of the existing literature regarding mechanical properties of the $\mathrm{PU}$ foams makes it possible to select the parameters with the greatest possible influence on the flexographic printing process, as well as to find the most suitable methods to investigate the effect of exploitation on sleeve properties. Another benefit lies in the knowledge of mechanisms of PU foam structure deformation which makes it possible to find the main causes of change in mechanical properties of the sleeves originating from the plate mounting/demounting and the printing process. As a large number of parameters influencing PU foam mechanical properties are fixed during printing, it can be concluded, through the review of the existing literature, that the main parameters to be investigated are the resilience of the sleeve compressible layer during cyclic compression testing (residual strain), maximum stress, Young's modulus, hysteresis loss, and creep and stress relaxation during cyclic compression testing with strain retention. These parameters should be selected as they are the ones mostly influenced by the changes in the PU foam structure and mechanical properties after exploitation. With that in mind, they can be used to pinpoint the main sources leading to the aforementioned changes, as well as the influence of those changes on other materials and parameters of importance to the flexographic printing process and cardboard packaging print quality.

\section{ACKNOWLEDGEMENTS}

This research has been supported by the Ministry of Education, Science and Technological Development through the project no. 451-03-68/2020-14/200156: "Innovative scientific and artistic research from the FTS domain".

\section{REFERENCES}

[1] Akindoyo, J. O., Beg, M. D. H., Ghazali, S., Islam, M. R., Jeyaratnam, N., Yuvaraj, A. R.: "Polyurethane types, synthesis and applications - A review", RCS Advances 115, 2016. doi: 10.1039/C6RA14525F

[2] Alkhader, M., Vural, M.: Mechanical response of cellular solids: "Role of cellular topology and microstructural irregularity", International Journal of Engineering Science 46 (10), 1035-1051, 2008. doi: 10.1016/j.ijengsci.2008.03.012

[3] Alzoubi, M. F., Al-Hallaj, S., Abu-Ayyad, M.: "Modeling of Compression Curves of Flexible Polyurethane Foam with Variable Density, Chemical Formulations and Strain Rates", Journal of Solid Mechanics 6 (1), 82-97, 2014. 
[4] Alzoubi, M. F., Tanbour, E. Y., Al-Waked, R.: "Compression and hysteresis curves of nonlinear polyurethane foams under different densities, strain rates and different environmental conditions", Proceeding of ASME - International Mechanical Engineering Congress \& Exposition, (ASME: Denver CO, USA, 2011), pages 101-109. doi: 10.1115/IMECE2011-62290

[5] Bergstrom, J. S., Boyce, M. C.: "Constitutive modelling of the large strain time-dependent behavior of elastomers", Journal of the Mechanics and Physics of Solids 46 (5), 931-954, 1998. doi: 10.1016/S0022-5096(97)00075-6

[6] Bouix, R., Viot, P., Lataillade, J.: "Polypropylene foam behavior under dynamic loadings: strain rate, density and microstructure effects", International Journal of Impact Engineering 36 (2), 329-342, 2009. doi: 10.1016/j.ijimpeng.2007.11.007

[7] Brydon, A. D., Bardenhagen, S. G., Miller, E. A., Seidler, G. T.: "Simulation of the densification of real open-celled foam microstructures", Journal of the Mechanics and Physics of Solids 53 (12), 26382660, 2005. doi: 10.1016/j.jmps.2005.07.007

[8] Cavender, K. D.: "New dynamic flexibility test. 1. Polyurethanes 90", Proceedings of the 33rd Annual Polyurethane Technical/Marketing Conference, (1990).

[9] Chakravarty, U., Mahfuz, H., Saha, M., Jeelani, S.: "Strain rate effects on sandwich core materials: an experimental and analytical investigation", Acta Materialia 51 (5), 1469-1479, 2003. doi: 10.1016/S1359-6454(02)00541-4

[10] Chattopadhyay, D., Webster, D. C.: "Thermal stability and flame retardancy of polyurethanes", Progress in Polymer Science 34 (10), 1068-1133, 2009. doi: 10.1016/j.progpolymsci.2009.06.002

[11] Chen, W., Hao, H., Hughes, D., Shi, Y., Cui, J., Li, Z. X.: "Static and dynamic mechanical properties of expanded polystyrene", Materials \& Design 69, 170-180, 2015. doi: 10.1016/j.matdes.2014.12.024

[12] Courtney, M. H., Charlton, L. J., Seal, K.: "Influence of foam density on automobile seat performance", Journal of Cellular Plastics 25 (5), 472-485, 1989. doi: 10.1177/0021955X8902500505

[13] Croop, B., Lobo, H.: "Selecting material models for the simulation of foams in LS-DYNA", Proceedings of 7th European LS-DYNA conference, (LS-DYNA: Salzburg, Austria, 2009), URL: https://www.dynalook.com/conferences/european-conf-2009/D-II-04.pdf (last request: 2019-09-27).

[14] de Vries, D.V.W.M.: "Characterization of polymeric foams", MSc Thesis, Eindhoven University of Technology, 2009.

[15] Derham, C. J.: "Creep and stress relaxation of rubbers - the effects of stress history and temperature changes", Journal of Materials Science 8 (7), 1023.-1029, 1973. doi:10.1007/BF00756634

[16] Di Landro, L., Sala, G., Olivieri, D.: "Deformation mechanisms and energy absorption of polystyrene foams for protective helmets", Polymer Testing 21 (2), 217-228, 2002. doi: 10.1016/S01429418(01)00073-3

[17] Dwyer, F. J.: "A review offactors affecting durability characteristics of flexible urethane foams", Journal of Cellular Plastics 12 (2), 104-113, 1976. doi: 10.1177/0021955X7601200205

[18] Engels, H.W., Pirkl, H. G., Albers, R., Albach, R. W., Krause, J., Hoffmann, A., Casselmann, H., Dormish, J.: "Polyurethanes: Versatile Materials and Sustainable Problem Solvers for Today's Challenges", Angewandte Chemie International Edition 52 (36), 9422-9441, 2013. doi: 10.1002/anie.201302766

[19] Gent, A. N., Thomas, A. G.: "Mechanics of foamed elastic materials", Rubber Chemistry and Technology 36 (3), 597-602, 1963. doi: 10.5254/1.3539591

[20] Gibson, I. J., Ashby, M. F.: "The mechanics of three-dimensional cellular materials", Proceedings of Royal Society of London 382 (1782), 1982. doi: 10.1098/rspa.1982.0088

[21] Gibson, L. J., Ashby, M. F.: “Cellular solids - Structure and properties", (Pergamon Press, Oxford, 1988.)

[22] Gibson, L. J., Ashby, M. F.: "Cellular solids - Structure and properties. 2nd edition”, (Cambridge University Press, Cambridge, 1999.)

[23] Gong, L., Kyriakides, S., Jang, W.- Y.: “Compressive response of open-cell foams. Part I: Morphology and elastic properties", International Journal of Solids and Structures 42 (5-6), 1355-1379, 2005. doi:10.1016/j.ijsolstr.2004.07.023

[24] Guo, Y., Li, Y.: "Quasi-static/dynamic response of SiO2-epoxy nanocomposites", Materials Science and Engineering: A 458 (1-2), 330-335, 2007. doi: 10.1016/j.msea.2007.02.011

[25] Jang, W. Y., Kraynik, A. M., Kyriakides, S.: "On the microstructure of open-cell foams and its effect on elastic properties", International Journal of Solids and Structures 45 (7-8), 1845-1875, 2008. doi: 10.1016/j.ijsolstr.2007.10.008 
[26] Izdebska, J., ŻołekTryznowska, Z., Świętoński, A.: "Correlation between plastic films properties and flexographic prints quality", Journal of Graphic Engineering and Design 6 (2), 19-25, 2015. ISSN: 2217-9860.

[27] Koohbor, B., Kidane, A., Lu, W. Y.: "Effect of specimen size, compressibility and inertia on the response of rigid polymer foams subjected to high velocity direct impact loading", International Journal of Impact Engineering 98, 62-74, 2016. doi: 10.1016/j.jimpeng.2016.08.006

[28] Koohbor, B., Ravindran, S., Kidane, A.: "Effects of cell-wall instability and local failure on the response of closed-cell polymeric foams subjected to dynamic loading", Mechanics of Materials 116, 67-76, 2018. doi:10.1016/j.mechmat.2017.03.017

[29] Kreter, P. E.: "Polyurethane foam properties as a function of foam density", Journal of Cellular Plastics 21 (5), 306-310, 1985. doi: 10.1177/0021955X8502100502

[30] Lee, W. M.: "A new approach to humid age compression set study in high resilient molded foams", Journal of Cellular Plastics 21 (6), 417-422, 1985. doi: 10.1177/0021955X8502100607

[31] Li, K., Gao, X. L., Roy, A. K.: "Micromechanics model for three-dimensional open-cell foams using a tetrakaidecahedral unit cell and Castigliano's second theorem", Composites Science and Technology 63 (12), 1769-1781, 2003. doi: 10.1016/S0266-3538(03)00117-9

[32] Lion, A.: "A constitutive model for carbon black filled rubber, experimental investigation and mathematical representation", Continuum Mechanics and Thermodynamics 8 (3), 153-169, 1996. doi: 10.1007/BF01181853

[33] Lu, W.- Y., Neidigk, M., Wyatt, N.: "Cyclic Loading Experiment for Characterizing Foam Viscoelastic Behavior", Experimental and Applied Mechanics 4, 135-144, 2016. doi:10.1007/978-3-319-42028$8 \_16$

[34] Lu, Z.X., Huang, J.X., Yuan, Z.S.: "Effects of microstructure on uniaxial strength asymmetry of opencell foams", Applied Mathematics and Mechanics 36 (1), 37-46, 2015. doi: 10.1007/s10483-0151893-9

[35] Markets and Markets: "Market Research Report", URL: https://www.marketsandmarkets.com/Market-Reports/polyurethane-foams-market1251.html?gclid=CjOKCQjwpfHzBRCiARIsAHHzyZqvSdW_pIDxDiu5vMypdy0OkMHDxp6gcecOJWOaAI Ly_I5h1Fz34x0aAgClEALw_wcB (last request: 2019-09-27).

[36] Mills, N.: "Polymer Foams Handbook - Engineering and Biomechanics Applications and Design Guide", (Butterworth-Heinemann, Oxford, 2007), doi: 10.1016/B978-0-7506-8069-1.X5000-4

[37] Mills, N. J., Stampfli, R., Marone, F., Bruhwiler, P. A.: "Finite element micromechanics model of impact compression of closed-cell polymer foams", International Journal of Solids and Structures 46 (3-4), 677-697, 2009. doi: 10.1016/j.ijsolstr.2008.09.012

[38] Molded Dimension, LLC.: "Creep and Stress Relaxation", URL: https://moldeddimensions.com/creepand-stress-relaxation.php (last request: 2019-09-27)

[39] Mondal, D. P., Goel, M. D., Das, S.: "Compressive deformation and energy absorption characteristics of closed-cell aluminum-fly ash particle composite foam", Materials Science and Engineering: A 507 (1-2), 102-109, 2009. doi: 10.1016/j.msea.2009.01.019

[40] Mulliken, A. D., Boyce, M. C.: "Mechanics of the rate-dependent elastic-plastic deformation of glassy polymers from low to high strain rates", International Journal of Solids and Structures 43 (5), 13311356, 2006. doi: 10.1016/j.ijsolstr.2005.04.016

[41] Nagy, A., Ko, W. L., Linholm, U. S.: "Mechanical behavior of foamed material under dynamic compression", Journal of Cellular Plastics 10 (3), 127-134, 1974. doi: 10.1177/0021955X7401000306

[42] Nakai, K., Yokoyama, T.: "Strain rate dependence of compressive stress-strain loops of several polymers", Journal of Solid Mechanics and Materials Engineering 2 (4), 557-566, 2008. doi: 10.1299/jmmp.2.557

[43] Omar, M. F., Akil, H. M., Ahmad, Z. A.: "Measurement and prediction of compressive properties of polymers at high strain rate loading", Materials \& Design 32 (8-9), 4207-4215, 2011a. doi:10.1016/j.matdes.2011.04.037

[44] Omar, M. F, Akil, H. M., Ahmad, Z. A.: "Static and dynamic compressive properties of mica/polypropylene composites", Materials Science and Engineering: A 528 (3), 1567-1576, 2011 b. doi: 10.1016/j.msea.2010.10.071

[45] Ouellet, S., Cronin, D., Worswick, M.: "Compressive response of polymeric foams under quasi-static, medium and high strain rate conditions", Polymer Testing 25 (6), 731-743, 2006. doi: 10.1016/j.polymertesting.2006.05.005 
[46] Pal, S., Maiti, S., Subhash, G.: "Effect of microscopic deformation mechanisms on the dynamic response of soft cellular materials", Mechanics of Materials 42 (2), 118-133, 2010. doi: 10.1016/j.mechmat.2009.11.014

[47] Perrot, C., Panneton, R., Olny, X.: "Periodic unit cell reconstruction of porous media: application to open-cell aluminum foams", Journal of Applied Physics 101 (11), 113538 - 113538-11, 2007. doi: 10.1063/1.2745095

[48] Petrů, M., Novák, O.: "Measurement and Numerical Modeling of Mechanical Properties of Polyurethane Foams", In: Faris Yilmaz. Aspects of Polyurethanes, (IntechOpen, 2017). doi: 10.5772/intechopen.69700

[49] Politis, A.: "Innovations in the graphic arts, media and packaging fields", Proceedings - The Ninth International Symposium GRID 2018, (GRID 2018: Novi Sad, Serbia, 2018). doi: 10.24867/GRID2018-p2

[50] Prisacariu, C.: "Polyurethane elastomers: from morphology to mechanical aspects", (Springer, Vienna, 2011). doi: 10.1007/978-3-7091-0514-6

[51] QFP: "Polyurethane Glosarry", URL: http://www.qualityfoam.com/polyurethane-glossary.asp (last request: 2019-09-27).

[52] Qi, H. J., Boyce, M. C.: "Stress-strain behavior of thermoplastic polyurethanes", Mechanics of Materials 37 (8), 817-839, 2005. doi: 10.1016/j.mechmat.2004.08.001

[53] Rafiee, Z.: "Synthesis and characterization of polyurethane/microcrystalline cellulose bionanocomposites", Progress in Organic Coatings 86, 190-193, 2015. doi: 10.1016/j.porgcoat.2015.05.013

[54] Randall, D., Lee, S.: "The Polyurethanes Book", (Wiley Ltd., New York, 2003).

[55] Río, G. D., Rodríguez, J.: "Compression yielding of polypropylenes above glass transition temperature", European Polymer Journal 46 (6), 1244-1250, 2010. doi: 10.1016/j.eurpolymj.2010.02.016

[56] Saint-Michel, F., Chazeau, L., Cavaillé, J.-Y., Chabert, E.: "Mechanical properties of high-density polyurethane foams: I. Effect of the density", Composites Science and Technology 66 (15), 27002708, 2006. doi:10.1016/j.compscitech.2006.03.009

[57] Sarva, S., Deschanel, S., Boyce, M., Chen, W.: "Stress-strain behavior of a polyurea and a polyurethane from low to high strain rates", Polymer 48 (8), 2208-2213, 2007. doi: 10.1016/j.polymer.2007.02.058

[58] Song, B., Chen, W. W., Dou, S., Winfree, N. A., Kang, J. H.: "Strain-rate effects on elastic and early cell-collapse responses of a polystyrene foam", International Journal of Impact Engineering 31 (5), 509-521, 2005. doi: 10.1016/j.ijimpeng.2004.02.003

[59] Sun, Y., Li, Q. M.: "Effect of entrapped gas on the dynamic compressive behavior of cellular solids", International Journal of Solids and Structures 63, 50-67, 2015. doi: 10.1016/j.ijsolstr.2015.02.034

[60] Szycher M.: "Szycher's Handbook of Polyurethanes. 2nd edition", (CRC Press, New York, 2006).

[61] Tedesco, J., Ross, C., Kuennen, S.: "Strain rate effects on the compressive strength of shockmitigating foams", Journal of Sound Vibration 165 (2), 376-384, 1993. doi: 10.1006/jsvi.1993.1265

[62] Tobushi, H., Hayashi, S., Endo, M., Shimada, D.: "Creep and Stress Relaxation of Polyurethane-Shape Memory Polymer Foam", Transactions of the Japan Society of Mechanical Engineers Series A 68 (676), 1788-1793, 2002. doi: 10.1299/kikaia.68.1788

[63] Wang, H., Zhou, H., Huang, Z., Zhang, Y., Qiao, H., Yu, Z.: "Experimental investigation and modeling of the mechanical behavior of PC/ABS during monotonic and cyclic loading", Polymer Testing 50, 216-223, 2016. doi: 10.1016/j.polymertesting. 2015.12.010

[64] Warren, W. E., Kraynik, A. M.: "The linear elastic properties of open-cell foams", Journal of Applied Mechanics 55 (2), 341-346, 1988. doi: 10.1115/1.3173680

[65] Wirpsza, Z., Kemp, T. J.: "Polyurethanes: chemistry, technology, and applications", (E. Horwood, New York, 1993).

[66] Yi, J., Boyce, M. C., Lee, G. F., Balizer, E.: "Large deformation rate-dependent stress-strain behavior of polyurea and polyurethanes", Polymer 47 (1), 319-329, 2006. doi: 10.1016/j.polymer.2005.10.107

[67] Yonezu, A., Hirayama, K., Kishida, H., Chen, X.: "Characterization of the compressive deformation behavior with strain rate effect of low-density polymeric foams", Polymer Testing 50, 1-8, 2016. doi: 10.1016/j.polymertesting.2015.11.021

[68] Zhao, H.: "Testing of polymeric foams at high and medium strain rates", Polymer Testing 16 (5), $507-$ 516, 1997. doi: 10.1016/S0142-9418(97)00012-3 
[69] Zia, K. M., Bhatti, H. N., Bhatti, I. A.: "Methods for polyurethane and polyurethane composites, recycling and recovery: A review", Reactive and Functional Polymers 67 (8), 675-692, 2007. doi: 10.1016/j.reactfunctpolym.2007.05.004

[70] Zia, K. M., Anjum, S., Zuber, M., Mujahid, M., Jamil, T.: "Synthesis and molecular characterization of chitosan based polyurethane elastomers using aromatic diisocyanate", International Journal of Biological Macromolecules 66, 26-32, 2014.

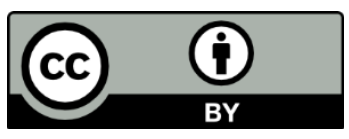

(C) 2020 Authors. Published by the University of Novi Sad, Faculty of Technical Sciences, Department of Graphic Engineering and Design. This article is an open access article distributed under the terms and conditions of the Creative Commons Attribution license 3.0 Serbia (http://creativecommons.org/licenses/by/3.0/rs/). 